\title{
Resources use, costs and effectiveness of non-penetrating deep sclerectomy according to glaucoma stage
}

\author{
Utilização de recursos, custos e efetividade da esclerectomia profunda não penetrante \\ de acordo com a gravidade do glaucoma
}

Ricardo Augusto Paletta Guedes ${ }^{1}$, Vanessa Maria Paletta Guedes ${ }^{1}$, Alfredo Chaoubah $^{2}$

\section{ABSTRACT}

Purpose: To assess the resources use, costs and effectiveness of non-penetrating deep sclerectomy (NPDS).

Methods: A retrospective cohort of NPDS patients was analyzed. Eyes were stratified according to glaucoma severity into 3 groups: 1 (early), 2 (moderate) and 3 (severe). NPDS associated resources were based on the frequency of the following variables: surgical procedure (NPDS), intraoperative mitomycin C (MMC); 5-fluorouracil needling (5-FU); Nd:YAG laser goniopuncture; new filtering surgery and medications needed postoperatively. Costs were based on the value and prices of the Brazilian Public Health System and follow-up period was 5 years. Success rate: percentage of patients achieving an end-point intraocular pressure $<18 \mathrm{mmHg}$ (and least 20\% reduction) without any medications.

Results: Percentage of patients using resources in groups 1,2 and 3 was, respectively: $92.1 \%, 88.5 \%$ and $93.0 \%$ for MMC; $10.5 \%, 11.5 \%$ and $13.3 \%$ for 5 -FU; $18.4 \%, 19.7 \%$ and $21.9 \%$ for goniopuncture and $13.2 \%, 24.6 \%$ and $27.3 \%$ for a new surgery. Mean number of glaucoma medications per patient at the end of follow-up was 0.42 in group 1 and 0.48 and 0.73 in groups 2 and 3, respectively. Mean NPDS direct cost was US\$305.25, US\$361.37 and US\$390.09 in early, moderate and severe glaucoma, respectively. No differences were found in effectiveness according to glaucoma severity. Conclusion: There is a trend in the use of resources and costs in NPDS. The more advanced the glaucoma, the higher the need for resources and the higher the associated costs. NPDS effectiveness did not differ among different glaucoma stages.

Keywords: Glaucoma; Primary open-angle glaucoma; Filtering surgery; Costs; Health care costs

\section{RESUMO}

Objetivo: Avaliar a utilização de recursos, os custos e a efetividade da esclerectomia profunda não penetrante (EPNP).

Métodos: Foi realizado um estudo retrospectivo consecutivo de olhos operados de glaucoma pela técnica de EPNP. Os olhos foram divididos em três grupos de acordo com a gravidade do glaucoma: 1 (inicial), 2 (moderado) e 3 (avançado). Os recursos considerados foram baseados nas seguintes variáveis: procedimento cirúrgico (EPNP), uso de mitomicina C (MMC) intraoperatória, agulhamento com 5-fluoruracil (5-FU), goniopuntura com Nd:YAG laser, nova cirurgia filtrante e medicações necessárias no pósoperatório. O cálculo dos custos foi baseado nos valores exercidos pelo Sistema Único de Saúde (SUS) no período de 5 anos. O sucesso foi considerado uma pressão intraocular final $<18 \mathrm{mmHg}$ (com pelo menos 20\% de redução) sem qualquer medicação antiglaucomatosa.

Resultados: A utilização proporcional de recursos nos grupos 1,2 3 foi, respectivamente: $92,1 \%, 88,5 \%$ e $93,0 \%$ para MMC; $10,5 \%, 11,5 \%$ e $13,3 \%$ para $5-F U ; 18,4 \%, 19,7 \%$ e $21,9 \%$ para goniopuntura e $13,2 \%, 24,6 \%$ e $27,3 \%$ para nova cirurgia filtrante. O custo direto da EPNP foi de US\$305,25 para os glaucomas iniciais; US\$361,37 para os moderados e US\$390,09 para os avançados. Não foi observada diferença na efetividade da cirurgia nos três grupos.

Conclusão: Observou-se uma tendência na utilização dos recursos e no custo direto da EPNP. Quanto mais avançado o glaucoma, maior foi a necessidade de recursos e maiores foram os custos. A efetividade da EPNP não sofreu influência do estágio evolutivo do glaucoma.

Descritores: Glaucoma; Glaucoma primário de ângulo aberto; Cirurgia filtrante; Custos; Custos de cuidados de saúde

\section{INTRODUCTION}

New treatment modalities need economic evaluation in order to facilitate decisions to better allocate health resources. Health technology assessment has great value due to enormous variability in clinical practice; uncertainty about the real impact of some diagnostic or therapeutic interventions; rapidity of incorporation and diffusion of new technologies and incompatibility between new and old technologies ${ }^{(1)}$.

The economic impact of the most prevalent eye diseases and their treatment is felt heavily by health services, especially in the case of glaucoma, the leading cause of irreversible blindness in the world ${ }^{(2)}$. And this trend is increasing, as both incidence and prevalence of glaucoma are expected to be higher in the future ${ }^{(3)}$.

Glaucoma-related costs tend to differ according to the severity of the disease. In the United States, Lee et al. found that these costs were lower in cases with early visual field damage and higher in more advanced cases $^{(4)}$. Traverso et al. found this same trend in Europe ${ }^{(5)}$.

Non-penetrating deep sclerectomy (NPDS) is a filtering glaucoma procedure, an alternative to trabeculectomy in patients with open-angle glaucoma ${ }^{(6,7)}$. Many studies published in the literature proved its efficacy and safety ${ }^{(8-10)}$.
Submitted for publication: February 7, 201

Accepted for publication: October 28, 2011

Study carried out at the Centro Oftalmológico Paletta Guedes and Universidade Federal de Juiz de Fora.

Physician, Centro Oftalmológico Paletta Guedes and Universidade Federal de Juiz de Fora - Juiz de Fora (MG), Brazil.

2 Professor, Statistic Department, Universidade Federal de Juiz de Fora - Juiz de Fora (MG), Brazil.
Funding: No specific financial support was available for this study.

Disclosure of potential conflicts of interest: R.A.P.Guedes, None; V.M.P.Guedes, None; A.Chaoubah, None.

Correspondence address: Ricardo Augusto Paletta Guedes. Av. Rio Branco, 2337 - grupo 801/ 807/808 - Juiz de Fora (MG) - 36010-905 - Brazil - E-mail: palettaguedes@yahoo.com 
It is unknown if the use of resources, the costs and effectiveness of NPDS are different according to glaucoma stage. The aim of this study is to compare the resources use, the costs and the effectiveness of NPDS in a group of operated eyes (stratified in early, moderate and severe glaucoma) and followed for 5 years.

\section{METHODS}

A retrospective study of a consecutive series of eyes undergoing NPDS from February 2000 to July 2007 was performed. Inclusion criteria were: history of primary open-angle glaucoma, no previous glaucoma filtering surgery and at least 5 years of follow-up after the surgery. If both eyes of a patient were eligible, we chose the first operated eye for this study. Exclusion criteria were: other types of glaucoma and previous filtering surgery.

The same surgical team performed all interventions in an outpatient setting.

Surgery was indicated whenever clinical control was not adequate for reaching the target IOP level. NPDS technique was performed as follows ${ }^{(7)}$ : Corneal traction with a 8.0 vicryl; fornix-based conjunctiva and Tenon's flap; application of mitomycin C (MMC) $(0.2 \mathrm{mg} / \mathrm{ml}$ for 3 minutes); superficial scleral flap $(5 \times 5 \mathrm{~mm})$ with one-third of the sclera thickness; a triangular-shaped deep scleral flap (as its dissection goes forward to the limbus, it opens the Schlemm's canal); sclerectomy of the deep scleral flap, promoting a good exposure of the trabeculo-descemetic window; peeling of the external trabecular membrane with a delicate forceps; repositioning of the superficial scleral flap with no sutures or implants and closing of the conjunctival flap with 8.0 vicryl stitches. As the authors do not use intrascleral implants, they chose not to suture the superficial scleral flap.

In the beginning of the study, MMC was used in those high-risk cases for bleb failure, which included: young patients ( $<45$ yearsold), black race, or previous manipulation of superior conjunctiva, use of topical medication for more than 5 years prior to the surgery. However, since 2002 the authors have used it in all cases, independently of the presence of factors for bleb failure.

Eyes were stratified, based on the Hoddap, Parrish and Anderson staging system ${ }^{(11,12)}$, into 3 groups according to glaucoma stage: early glaucoma (group 1), moderate glaucoma (group 2), and severe glaucoma (group 3).

Resource use variables were: use of mitomycin C (MMC) intraoperatively; number of 5-fluorouracil (5-FU) injections postoperatively; number of Nd:YAG laser goniopunctures postoperatively; number of reoperations (new filtering procedure) needed and mean number of anti-glaucoma medications needed postoperatively.

We have calculated the direct costs related to NPDS through the following variables in a 5-year follow-up:

- Price of NPDS paid by the Brazilian Public National Health System (SUS). Prices were obtained through the internet in the SIGTAP table ${ }^{(13)}$;

Price and number of MMC units used intraoperatively;

- Price and number of medications used in the postoperative period. The authors estimated 1 bottle of $0.3 \%$ ciprofloxacin and 2 bottles of $0.1 \%$ dexamethasone per surgical intervention. Another bottle of steroid was also included for goniopuncture or when 5-FU injections were needed;

- Price and number of 5-FU injections;

- Price and number of Nd:YAG laser goniopunctures;

- Price and number of surgical reinterventions;

- Price, number and type of glaucoma medications needed after surgery and for how long this medication was necessary for up to 5 years of follow-up.

Effectiveness was defined as the mean percentage of intraocular pressure (IOP) reduction from the preoperative period to the end of follow-up (5 years). We also calculated the complete success rate (IOP $<18 \mathrm{mmHg}$ and at least 20\% reduction from baseline without any medication) for each one of the groups.

Comparisons among the studied groups were done using Student T, Anova and Chi-square tests with a significance of $95 \%$.

Statistical analysis was performed using SPSS 13.0 (SPSS Inc., Chicago, Illinois, USA).

This study adhered to the tenets of the Declaration of Helsinki.

\section{RESULTS}

Two-hundred twenty-seven eyes met the inclusion criteria and were evaluated in this study. Thirty-eight eyes had early glaucoma (group 1), 61 eyes had moderate glaucoma (group 2) and 128 eyes had severe glaucoma (group 3).

Preoperative characteristics (age, race, mean preoperative number of medications, mean preoperative IOP, mean preoperative cup-to-disc vertical ratio) of the studied groups are presented in table 1. The number of white patients was 161. The age of the patients ranged from 31 to 95 years. The mean age of group 3 was higher than groups 1 and 2 and mean age of group 2 was higher than group 1.

Postoperative mean number of medications and postoperative mean IOP showed a statistically significant reduction from preoperative values. Comparisons are presented in table 2 .

In our study, mean number of MMC use, 5-FU needling, YAG-laser goniopuncture, surgical reinterventions and number of medications did not show a statistically significant difference according to glaucoma stage (refer to table 3). However, there is a trend of a higher need for resources as glaucoma is more severe, when we consider mean number of 5-FU needling, YAG-laser goniopuncture, surgical re-interventions (Figure 1).

Table 4 displays the composition of NPDS costs. Mean cost for NPDS in severe glaucoma was higher than in moderate and early glaucoma. There was a slightly trend toward increase in costs according to glaucoma stage (Figure 2). When resources are considered, the more advanced the glaucoma, more costly the surgical procedure (NPDS). Although the difference was not statistically significant ( $p=0.10$, ANOVA test), it is marginally significant and may be clinically relevant from the payers' perspective.

Effectiveness (mean percentage of IOP reduction from preoperative IOP to final IOP) in groups 1, 2 and 3 are respectively: $42.22 \%$, $39.54 \%$ and $48.52 \%$. Complete success rate was $73.7 \%, 63.9 \%$ and $68.5 \%$ in groups 1,2 and 3 , respectively $(p=0.57)$.

\section{DISCUSSION}

Our results show that there is a slightly trend in NPDS costs according to glaucoma stage ( $p=0.10$, a weak statistically signifi-

Table 1. Preoperative characteristics of the studied population, according to glaucoma stage

\begin{tabular}{lcccc}
\hline & \multicolumn{3}{c}{ Glaucoma stage* } & \\
\cline { 2 - 4 } Characteristics & $\begin{array}{c}\text { Early } \\
\text { (n=38) }\end{array}$ & $\begin{array}{c}\text { Moderate } \\
\text { (n=61) }\end{array}$ & $\begin{array}{l}\text { Severe } \\
\text { (n=128) }\end{array}$ & p value \\
\hline Age (years) & 56.97 & 63.03 & 66.70 & $<0.0001$ \\
Race Whites & $16.8 \%$ & $26.1 \%$ & $57.1 \%$ & 0.91 \\
Mean number of medications & $16.7 \%$ & $28.8 \%$ & $54.5 \%$ & \\
Mean IOP (mmHg) & 2.61 & 2.75 & 2.79 & 0.29 \\
Mean C/D & 23.92 & 22.13 & 24.63 & 0.00 \\
& 0.52 & 0.68 & 0.85 & $<0.0001$ \\
\hline
\end{tabular}

$\mathrm{IOP}=$ intraocular pressure; $C / D=$ vertical cup-to-disc ratio; $\mathrm{p}=$ statistical significance (Anova and Chi-square)

* = Hoddap, Parrish and Anderson staging system ${ }^{(11)}$

** = Non-whites included blacks and mixed blacks and whites 
Table 2. Pre and postoperative comparisons of mean number of medications per patient, mean intraocular pressure and mean cup-to-disc ratio, according to glaucoma stage

\begin{tabular}{|c|c|c|c|c|c|c|c|c|c|}
\hline \multirow{3}{*}{$\begin{array}{l}\text { Glaucoma } \\
\text { stage* }\end{array}$} & \multicolumn{9}{|c|}{ Comparisons from baseline to the end of follow-up } \\
\hline & \multicolumn{3}{|c|}{ Number of medications } & \multicolumn{3}{|c|}{ IOP (mmHg) } & \multicolumn{3}{|c|}{ C/D } \\
\hline & Baseline & Final & $p$ value & Baseline & Final & $\overline{p \text { value }}$ & Baseline & Final & $\overline{p \text { value }}$ \\
\hline Early & 2.61 & 0.42 & $<0.0001$ & 23.92 & 13.82 & $<0.0001$ & 0.52 & 0.52 & 0.16 \\
\hline Moderate & 2.75 & 0.48 & $<0.0001$ & 22.13 & 13.48 & $<0.0001$ & 0.68 & 0.68 & 0.32 \\
\hline Severe & 2.79 & 0.73 & $<0.0001$ & 24.63 & 12.64 & $<0.0001$ & 0.85 & 0.85 & 0.04 \\
\hline
\end{tabular}

$\mathrm{IOP}=$ intraocular pressure; $\mathrm{C} / \mathrm{D}=$ vertical cup-to-disc ratio; $\mathrm{p}=$ statistical significance (Student $\mathrm{T}$ test for paired samples)

* =Hoddap, Parrish and Anderson staging system ${ }^{(11)}$

Table 3. Use of resources according to glaucoma stage

\begin{tabular}{|c|c|c|c|c|}
\hline \multirow[b]{2}{*}{ Resources } & \multicolumn{3}{|c|}{ Glaucoma stage* } & \multirow[b]{2}{*}{ p value } \\
\hline & Early & Moderate & Severe & \\
\hline MMC - proportion of patients & $35 / 38(92.1 \%)$ & $54 / 61(88.5 \%)$ & $119 / 128(93.0 \%)$ & 0.58 \\
\hline 5-FU needling - proportion of patients & $4 / 38(10.5 \%)$ & 7/61 (11.5\%) & 17/128 (13.3\%) & 0.87 \\
\hline Goniopuncture - proportion of patients & $7 / 38(18.4 \%)$ & 12/61 (19.7\%) & 28/128 (21.9\%) & 0.87 \\
\hline New surgery - proportion of patients & $5 / 38(13.2 \%)$ & $15 / 61(24.6 \%)$ & $35 / 128(27.3 \%)$ & 0.20 \\
\hline Mean number of medications & 0.42 & 0.48 & 0.73 & 0.08 \\
\hline
\end{tabular}

$\mathrm{MMC}=$ mitomycin C used intraoperatively; 5 -FU = 5 fluorouracil; $\mathrm{p}=$ statistical significance (Anova and Chi-square)

* $=$ Hoddap, Parrish and Anderson staging system ${ }^{(11)}$

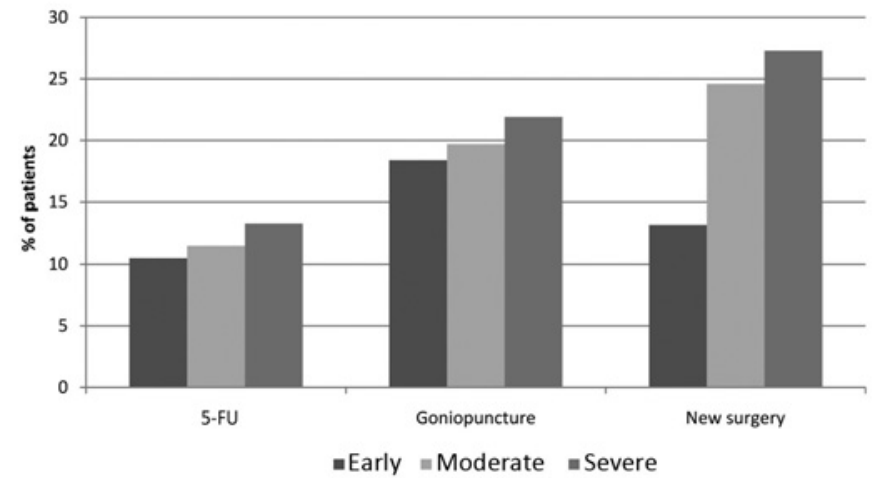

Figure 1. Percentage of 5-FU injections, goniopuncture and new surgery according to glaucoma stage.

cance). The more advanced the glaucoma, the higher are the associated costs. Clinically, NPDS achieved the same success rate in all glaucoma stages. Therefore, in more severe glaucomas this higher use of resources and costs resulted in an effective and comparable IOP control up to 5 years of follow-up.

The studied population was homogeneous in race and mean number of medications prior to surgery. Those two were potential confounding variables, as they might lead to differences in wound healing response ${ }^{(14,15)}$ and, therefore, the number of resources used, mainly MMC and 5-FU injections.

Differences among the studied groups (early, moderate and severe glaucoma) were found in age, mean preoperative IOP and cup-to-disc vertical ratio. Age could influence the use of resources, as the younger the patient, the more postoperative fibroblastic reaction is expected ${ }^{(14,16)}$. However, this effect was not observed. According to our results, early glaucoma patients tended to use fewer resources. This might be explained by the very similar mean ages in the studied groups (56.97; 63.03 and 66.70 years, respectively in early, moderate and severe glaucoma). This difference was statistically, but not clinically significant.
In spite of some criticism concerning Hoddap, Parrish and Anderson glaucoma staging system ${ }^{(12)}$, we chose to use it because it is the most spread and easy to apply one.

Significant reduction from baseline to the end of follow-up was observed in both mean number of medications and IOP. Mean percentage of IOP reduction and success rate was not statistically different among groups. Complete success rate was 73.7\%, 63.9\% and $68.5 \%$ in early, moderate and severe glaucoma, respectively $(p=0.57)$. Our results are comparable to the published literature ${ }^{(6-10)}$.

Although not statistically significant, early glaucoma showed a fewer need for resources use, in order to achieve the same success rate, than moderate and severe glaucoma. Severe glaucoma used proportionally more resources than early and moderate glaucoma. We observed a trend in all resources (5-FU, Nd:YAG laser goniopuncture, need for a new glaucoma surgical procedure and mean number of medications), except one (MMC). The percentage of patients needing a 5-FU needling in the postoperative period was $10.5 \%$ in early glaucoma, $11.5 \%$ in moderate glaucoma and $13.3 \%$ in severe glaucoma. The percentage of patients that underwent a goniopuncture was $18.4 \%, 19.7 \%$ and $21.9 \%$ in early, moderate and severe glaucoma, respectively. The need for a new glaucoma surgery does also differ according to glaucoma stage. In early glaucoma, $13.2 \%$ of patients needed a new filtering procedure. In moderate and severe glaucoma, this number was up to $24.6 \%$ and $27.3 \%$, respectively. Despite a significant reduction in the mean number of medications in all groups from baseline, we observed that the more advanced the glaucoma, the higher the mean number of glaucoma medications in the postoperative period.

This trend was not observed for MMC. This was because the use of $\mathrm{MMC}$ is based on the preoperative estimation of risk for failure according to several parameters, such as race, age, number of preoperative glaucoma medications, prior ophthalmic surgery, among others ${ }^{(14)}$

Although none of the resources comparisons among glaucoma stages obtained statistical significance, from the economic perspective it can cause a great deal of influence. The Brazilian Public Health System (SUS) pays the amount of US\$ 147.27 for each glaucoma surgery ${ }^{(13)}$, however the total direct surgical cost when resour- 
Table 4. Non-penetrating deep sclerectomy resources use and direct costs according to glaucoma stage

\begin{tabular}{|c|c|c|c|c|c|c|c|c|}
\hline & & \multicolumn{7}{|c|}{ Glaucoma stage* } \\
\hline \multirow{2}{*}{\multicolumn{2}{|c|}{$\begin{array}{l}\text { NPDS cost } \\
\text { composition }\end{array}$}} & \multirow[b]{2}{*}{ Unit cost (US\$) } & \multicolumn{2}{|c|}{ Early } & \multicolumn{2}{|c|}{ Moderate } & \multicolumn{2}{|c|}{ Severe } \\
\hline & & & Units & Total cost (US\$) & Units & Total cost (US\$) & Units & Total cost (US\$) \\
\hline NPDS & & 147.27 & 38 & $5,596.26$ & 61 & $8,983.47$ & 128 & $18,850.56$ \\
\hline \multirow[t]{5}{*}{ Resources } & MMC & 30.10 & 35 & $1,053.50$ & 54 & $1,625.40$ & 119 & $3,581.90$ \\
\hline & $5-\mathrm{FU}$ & 14.02 & 4 & 56.08 & 7 & 98.14 & 17 & 238.34 \\
\hline & Goniopuncture & 15.91 & 7 & 111.37 & 12 & 190.92 & 28 & 445.48 \\
\hline & New surgery & 147.27 & 5 & 736.35 & 15 & $2,209.05$ & 35 & $5,154.45$ \\
\hline & Medications ${ }^{\S}$ & NA & NA & $3,004.31$ & NA & $7,304.40$ & NA & $18,204.52$ \\
\hline \multicolumn{2}{|c|}{ Total cost } & NA & NA & $11,599.32$ & NA & $22,043.59$ & NA & $49,931.25$ \\
\hline \multicolumn{2}{|c|}{ Total cost per eye } & NA & NA & 305.25 & NA & 361.37 & NA & 390.09 \\
\hline
\end{tabular}

${ }^{5}=$ medications costs included all necessary antibiotics, steroids and any hypotensive agents in the postoperative period up to 5 years of follow-up; NPDS= non-penetrating deep sclerectomy; $\mathrm{MMC}=$ mitomycin C used intraoperatively; $5-\mathrm{FU}=5$ fluorouracil needling; $\mathrm{NA}=$ not applicable

* Hoddap, Parrish and Anderson staging system ${ }^{(11)}$

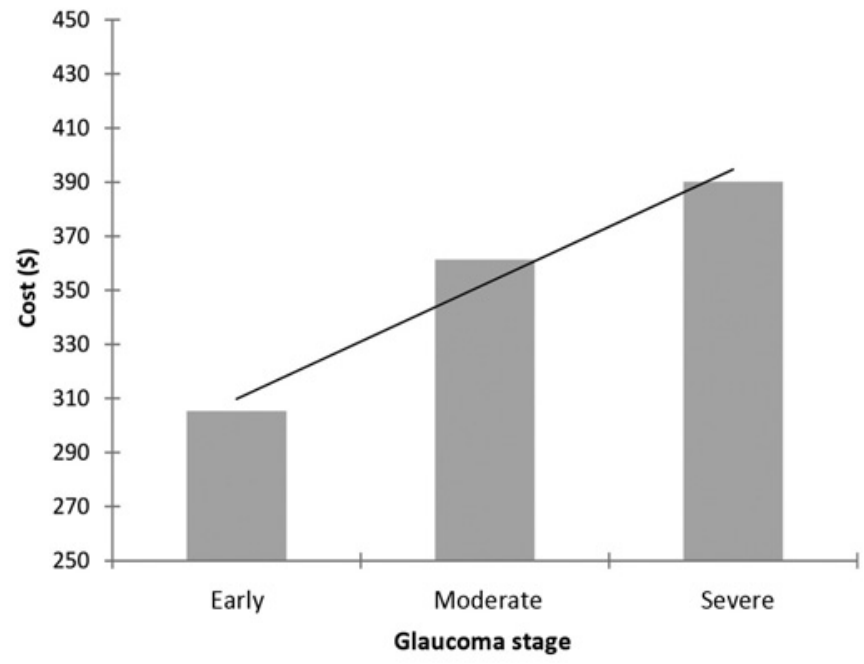

Figure 2. Trend in NPDS direct costs per patient according to glaucoma stage $(p=0.10)$.

ces costs are incorporated is different. Mean total cost per operated eye in the early glaucoma group was US\$305.25. In moderate and severe glaucomas, this cost was US\$ 361.37 and US\$ 390.09, respectively $(p=0.10)$.

Performing NPDS in early glaucoma can generate cost savings of approximately US\$85.00 per patient compared to severe glaucoma, with a much lesser need of postoperative reinterventions (5-FU needling [10.5\% versus $13.3 \%]$, goniopuncture [18.4\% versus $21.9 \%]$ and new filtering procedure [13.2\% versus 27.3\%]). It is expected that the lesser the need for postoperative reinterventions, the better the quality of life of patients.

Glaucoma direct costs have an enormous impact on health care, because it includes: chronic use of medications, surgical procedures, medical visits and frequent exams ${ }^{(5)}$. Glaucoma chargers are responsible for up to $12 \%$ of all medical expenses in glaucoma patients ${ }^{(17)}$. Medications contribute with a significant proportion of glaucoma related direct costs ${ }^{(4,5)}$. Rylander and Vold estimated the annual costs with a single medication in the United States. It varied from US\$150.81 to US\$ $873.98^{(18)}$. If a patient needs more than one medication, which is not unusual ${ }^{(19,20)}$, theses costs are even higher.

In our current world's ever-limiting health care budget, economic assessment of different treatment options are very useful and may help decision makers to advice the most suitable one for each environment. Brazilian's Health Care System (SUS) cannot afford to keep every glaucoma patient under chronic use of medications.
Besides some problems associated with this chronic regimen (persistence, adherence, side effects, etc) ${ }^{(21,22)}$, the costs of such strategy are extremely high. From the public health perspective, a cost-effective analysis of medications versus surgery can help health care policy and decision makers decide the most suitable treatment. We are currently working on a project on the cost-effectiveness analysis of different glaucoma treatments in Brazil.

Costs in glaucoma vary a lot according to glaucoma stage ${ }^{(4,5)}$. Lee et al. found that an early glaucoma costs in average US\$ 623.00 and an end-stage disease can achieve values of US\$2,511.00 ${ }^{(4)}$. Comparable results were obtained by Traverso et al., assessing glaucoma costs in Europe ${ }^{(5)}$. Surgical costs comparisons to these two studies are difficult to perform, as in these previous studies, global direct costs were assessed (including medications, consultations, exams and surgeries by various techniques) and in our study we only focused on NPDS direct costs.

There is evidence that glaucoma medications are the major responsible for the total cost in every stage of glaucoma ${ }^{(4,5)}$. That is why it is important that, from the economic point of view, surgery should be considered earlier in the glaucoma treatment. When we look only at the surgery-related costs, as we did in our study, we see that costs are lower in the earlier stages of the disease.

NPDS has some advantages over trabeculectomy that can encourage physicians to early indicate surgery. It has the same ability to control IOP, as demonstrated in several studies around the world ${ }^{(8,9)}$. At the same time, it shows fewer complications, making it a safer procedure ${ }^{(6-10)}$. When performed in early glaucoma cases, NPDS can also be a cost saving procedure.

In summary, NPDS comparative effectiveness is similar in all severity stages of glaucoma. Conversely, there is a trend toward the use of resources and associated costs in NPDS. A more advanced glaucoma tends to need more resources and postoperative reinterventions than an earlier one. Accordingly, NPDS associated direct costs are significantly higher in more severe glaucoma.

\section{REFERENCES}

1. Banta HD, Luce BR. Health care technology and it is assessment: an international perspective. Oxford: Oxford University Press; 1993

2. Resnikoff S, Pascolini D, Etya'ale D, Kocur I, Pararajasegaram R, Pokharel GP, et al. Global data on visual impairment in the year 2002. Bull World Health Organ. 2004:82(11):844-51.

3. Quigley HA, Broman AT. The number of people with glaucoma worldwide in 2010 and 2020. Br J Ophthalmol. 2006;90(3):262-7.

4. Lee PP, Walt JG, Doyle JJ, Kotak SV, Evans SJ, Budenz DL, et al. A multicenter, retrospective pilot study of resource use and costs associated with severity of disease in glaucoma. Arch Ophthalmol. 2006;124(1):12-9.

5. Traverso CE, Walt JG, Kelly SP, Hommer AH, Bron AM, Denis P, et al. Direct costs of glaucoma and severity of the disease: a multinational long term study of resource utilisation in Europe. Br J Ophthalmol. 2005;89(10):1245-9. 
6. Mendrinos E, Mermoud A, Shaarawy T. Nonpenetrating glaucoma surgery. Surv Ophthalmol. 2008:53(6):592-630

7. Guedes RAP, Guedes VMP. Cirurgia filtrantes não penetrante: conceito, técnicas e resultados. Arq Bras Oftalmol. 2006;69(4):605-13.

8. Cheng JW, Xi GL, Wei RL, Cai JP, Li Y. Efficacy and tolerability of nonpenetrating glaucoma surgery augmented with mitomycin C in treatment of open-angle glaucoma: a metaanalysis. Can J Ophthalmol. 2009;44(1):76-82.

9. Hondur A, Onol M, Hasanreisoglu B. Nonpenetrating glaucoma surgery: meta-analysis of recent results. J Glaucoma. 2008;17(2):139-46. Comment in J Glaucoma. 2008;17(7):601-2; author reply 603-4.

10. Bissig A, Rivier D, Zaninetti M, Shaarawy T, Mermoud A, Roy S. Ten years follow-up after deep sclerectomy with collagen implant. J Glaucoma. 2008;17(8):680-6.

11. Hodapp E, Parrish RK, Anderson DR. Clinical decisions in glaucoma. St. Louis: Mosby; 1993. p.52-61.

12. Susanna R Jr, Vessani RM. Staging glaucoma patient: why and how? Open Ophthalmol J. 2009:3:59-64.

13. Brasil. Ministério da Saúde. DATASUS. Tabela de Procedimentos do Sistema Único de Saúde. SIGTAP. Available at: http://w3.datasus.gov.br/siasih/siasih.php. Access in January 30 30 th 2010.

14. European Glaucoma Society. Terminology and guidelines for glaucoma. $2^{\text {nd }}$ ed. Savona, Italy: Dogma; 2003.

15. Lavin MJ, Wormald RP, Migdal CS, Hitchings RA. The influence of prior therapy on the success of trabeculectomy. Arch Ophthalmol. 1990;108(11):1543-8.
16. CAT-152 Trabeculectomy Study Group, Grehn F, Holló G, Khaw P, Overton B, Wilson R Vogel R, Smith Z. Factors affecting the outcome of trabeculectomy: an analysis based on combined data from two phase III studies of an antibody to transforming growth factor beta2,CAT-152. Ophthalmology. 2007;114(10):1831-8.

17. Lee PP, Levin LA, Walt JG, Chiang T, Katz LM, Dolgitser M, et al. Cost of patients with primary open-angle glaucoma: a retrospective study of commercial insurance claims data. Ophthalmology. 2007;114(7):1241-7.

18. Rylander NR, Vold SD. Cost analysis of glaucoma medications. Am J Ophthalmol. 2008; 145(1):106-13. Comment in Am J Ophthalmol. 2008;145(6):1108-9; author reply 1109.

19. Kass MA, Heuer DK, Higginbotham EJ, Johnson CA, Keltner JL, Miller JP, et al. The Ocular Hypertension Treatment Study: a randomized trial determines that topical ocular hypotensive medication delays or prevents the onset of primary open-angle glaucoma. Arch Ophthalmol. 2002;120(6):701-13; discussion 829-30.

20. Lichter PR, Musch DC, Gillespie BW, Guire KE, Janz NK, Wren PA, Mills RP: CIGTS Study Group. Interim clinical outcomes in the Collaborative Initial Glaucoma Treatment Study comparing initial treatment randomized to medications or surgery. Ophthalmology. 2001;108(11):1943-53.

21. Reardon G, Schwartz GF, Mozaffari E. Patient persistency with topical ocular hypotensive therapy in a managed care population. Am J Ophthalmol. 2004;137(1 Suppl):S3-12.

22. Schwartz GF, Quigley HA. Adherence and persistence with glaucoma therapy. Surv Opththalmol. 2008;53 Suppl 1:S57-68. 